\title{
EXTRACTION, CHARACTERIZATION AND INVITRO BIOACTIVITY EVALUATION OF ALKALOIDS, FLAVONOIDS, SAPONINS AND TANNINS OF Cassia alata, Thespesia populnea, Euphorbia hirta AND Wrightia tinctoria
}

\author{
P. Raji, Antony V. Samrot*, D. Bennet Rohan, M. Divya Kumar, \\ Ratna Geetika, V. Kripu Sharma and D. Keerthana \\ Department of Biotechnology, School of Bio and Chemical Engineering, Sathyabama Institute of \\ Science and Technology, Jeppiaar Nagar, Chennai-600 119, Tamil Nadu, India \\ *E-mail: antonysamrot@gmail.com
}

\begin{abstract}
The use of medicinal plants to treat infections as a practice can be witnessed since the prehistoric era. Even as on date three-quarter of the world's population totally depends on plants for their primary health care benefits. In this study, secondary metabolites like alkaloids, flavonoids, tannins and saponins were extracted from four medicinal plants viz. Cassia alata, Thespesia populnea, Euphorbia hirta and Wrightia tinctoria and characterized by UV, TLC, FTIR and GCMS analysis. The metabolites were checked for the antibacterial activity using agar well diffusion method and swarming motility assay against Pseudomonas aeruginosa. The alkaloids and saponins of Cassia alata, Euphorbia hirta, Thespesia populnea and Wrightia tinctorial showed dose-response antibacterial activity. The highest antibacterial activity of $1.9 \mathrm{~cm}$ was seen for the tannin of Wrightia tinctoria and saponin of Euphorbia hirtaat $16 \mu \mathrm{g}$ concentration. Flavonoid of Euphorbia hirta, Cassia alata and Wrightia tinctorial showed good percentage inhibition of free radicals in DPPH scavenging assay supportive of the antioxidant property. The highest percentage inhibition of $88.75 \%$ was noted for tannin of Euphorbia hirta at $50 \mu \mathrm{g}$ concentration. Antioxidant activity was also checked qualitatively by TLC bioautography and quantitatively for its reducing power on the free radicals by FRAP and phosphomolybdenum assay. The extracted metabolites especially alkaloids were able to restrict the movement of micro organisms to a confined space which was evident from the swarming test.
\end{abstract}

Keywords: Alkaloid; flavonoids; tannin; saponin; antibacterial; antioxidant

(C) RASĀYAN. All rights reserved

\section{INTRODUCTION}

The growing mode of plants as fixed to one place has left it defenseless against many predators like animals, insects and microbes. Furthermore, they are to prove their ecological succession by overthrowing competition from the germinating neighbors which subsequently has led to the evolution of certain molecules as phytoprotectants. ${ }^{1}$ These phytochemicals are modified products obtained by chemical reactions like methylation, hydroxylation and glycosylation from the precursor molecules like carbohydrates, proteins, lipids and nucleic acids which are primary for the plant survival. ${ }^{2}$ Secondary metabolites do have other functions as UV protectants, attractants of pollinating insects and many more. ${ }^{3}$ Based on the chemical structure, composition, solubility and biochemical synthesis the secondary metabolites are broadly classified as terpenes, phenolics, nitrogen and sulphur containing compounds. ${ }^{4}$ The pharmacological activity of a plant depends on its phytochemicals either as a single molecule or combinations. The flavonoid, for instance, are polyphenolic molecules with a hydroxyl group placed in different positions conferring various activity like antioxidant, antimicrobial, enzyme inhibitory, antiinflammatory, oestrogenic, anti-allergic, vascular and cytotoxic antitumor activity. ${ }^{5}$ Recent reports revealed that phenolic components like flavonoids possibly form a complex with the calcium and potassium oxalates which could provide a potential cure for treating kidney stones. ${ }^{6}$ Alkaloids, on the Rasayan J. Chem., 12(1), 123-137(2019) http://dx.doi.org/10.31788/RJC.2019.1214054

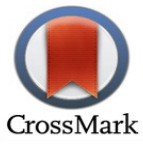


other hand, mimics the neuro transmitters' as agonists or antagonists in binding to the molecular receptors and their usage dates back to more than 5000 years as hallucinogens and psychotropic drugs. ${ }^{7}$ Tannins enriched plant extracts are mostly used by the traditional practitioners as astringents, diuretics, to treat diarrhoea, to reduce ulceration of tumor tissues of the stomach and duodenum. ${ }^{8}$ Saponins are found to possess anti-inflammatory activity and a major constituent used in the Chinese and Japanese system of medicine $^{9}$ and there are numerous plants yet to be explored for its therapeutic value through metabolite profiling. It is also interesting to recognize that higher concentration of metabolites always does not correlate with the better activity. ${ }^{10}$ The current work is a comprehensive report of four plants of Indian origin, namely Cassia alata Linn, Thespesia populnea, Euphorbia hirtaand Wrightia tinctoria. The layout of the work includes isolation and characterization of secondary metabolites like Alkaloids, saponins, tannins and flavonoids by instrumental analysis (UV, FTIR, GCMS) and also to evaluate its antibacterial and antioxidant potentials.

\section{Collection and Extraction}

\section{EXPERIMENTAL}

The plant material from in and around Chennai region was collected, washed, dried, powdered and preserved for further analysis. Based on the organoleptic and macroscopic examination, the samples were examined and authenticated by Dr. P Jayaraman, Director, Plant Anatomy Research Centre, Chennai, Tamil Nadu, India.

\section{Extraction of Metabolites}

The Alkaloids were obtained by treating the plant material with $10 \%$ acidified alcohol and ammonium hydroxide, which resulted in precipitated forms of the desired material. ${ }^{11}$ While Flavonoids were extracted from the macerated leaf powders following the procedures of Victorio et al ${ }^{12}$ with some modifications and Saponins were separated by counter extracting the alcoholic plant extracts with 50ml of diethyl ether and $60 \mathrm{ml}$ of $\mathrm{N}$-butanol. The mixture was washed twice with $10 \mathrm{ml}$ of $5 \% \mathrm{NaCl}$. Tannins were extracted by continuous treatment of aqueous extract with ethyl acetate and kept in a shaker for 30 minutes with an optimum $\mathrm{pH}$ maintained by adding concentrated hydrochloric acid ${ }^{11}$ secondary metabolites thus obtained were concentrated and preserved for further use.

\section{Characterization of Metabolites \\ UV-Visible Spectroscopy Analysis}

The samples were observed under the spectral range of 200 to 700nm in UV-1800, Shimadzu, Japan. Characteristics peaks were obtained for the different functional groups. ${ }^{13}$

\section{Fourier Transform Infra-Red Spectroscopy}

The dried plant extract is pressed to a pellet by mixing it with $\mathrm{KBr}$ in the ratio of 1:100 which was taken in a sample holder of Perkin Elmer Spectrophotometer (Spectrum RX1, FT-IR V.2.0) and operated in the range $4000-480 \mathrm{~cm}-1$. The functional groups were inferred from the spectral data.

\section{GC- MS Analysis}

Plant metabolites were analyzed by injecting $2.0 \mu \mathrm{l}$ of the sample onto the helium mobile phase with a flow rate of $1.0 \mathrm{ml} / \mathrm{min}$ heated to a temperature of $290^{\circ} \mathrm{C}$ (Shimadzu, Japan). The experimental procedures were scanned of range $40-600 \mathrm{~m} / \mathrm{z}$ for 0.5 second interval. The chromatogram results were interpreted and compared to Wiley Spectral library search engines. ${ }^{14}$

\section{Separation of Compounds by Thin Layer Chromatography of Metabolites}

Each metabolite was characterized preliminarily using Thin Layer Chromatography with combination of solvent systems like methanol and ammonium hydroxide in the ratio of 9.5:0.5 for Alkaloids; ethyl acetate: formic acid: acetic acid: water (7:0.5:0.5:2) for Flavonoids; chloroform: glacial acetic acid: methanol: water (6:3.2:1.2:0.8) for Saponins and the chromatogram was visualized under white light and UV light for detectable bands. Spots were laid on silica plate and Tannins was identified as purple spots upon UV exposure. . $^{15,16}$ 
RASĀYAN J. Chem.

Vol. 12 | No. 1 |123 - 137| January - March | 2019

\begin{abstract}
Invitro Antibacterial Activity
Agar Well Diffusion Method

Antibacterial activity of various metabolites was determined by agar well diffusion method. The inhibition zones were reported in centimeter $(\mathrm{cm})$ against the test organism Pseudomonas aeruginosa. Erythromycin was used as positive control and the respective solvent as negative control. ${ }^{17}$
\end{abstract}

\title{
Swarming Motility Assay
}

The motility assay for metabolites was carried out in petri dishes having soft agar medium and inoculated with $5 \mu$ l of Pseudomonas aeruginosa strains in the center. Swarming motility of a prokaryote under the influence of secondary metabolites was assessed as growth on the surface of a nutritive medium in a given time at $37^{\circ} \mathrm{C} .^{18-20}$

\section{Antioxidant Activity of the Plant Extracts}

\section{TLC Bioautography for Antioxidant Activity of the Metabolite}

Developed TLC plates were dried, sprayed with DPPH solution to find the antioxidant molecule in the metabolites as per our previous reported procedures. ${ }^{21}$

\section{Scavenging Assay and Reducing Assay for Antioxidant Activity}

The antioxidant property pronounced through reducing or scavenging effect of the free radicals was checked by FRAP ${ }^{22,23}, \mathrm{DPPH}^{24}$ and Phosphomolydenum assay. ${ }^{22,25}$ Appropriate concentrations of ascorbic acid were used as a standard.

\section{Characterization of Metabolites Using UV Spectroscopy \\ RESULT AND DISCUSSION}

The alkaloids, flavonoids, tannins and saponins isolated from the plants were subjected to spectroscopic analysis. The presence of individual molecules resulted in the absorption maxima of the incident rays with characteristic peaks. The UV vis spectral profile of the alkaloid sample recorded peaks at $400 \mathrm{~nm}$ and 650 $\mathrm{nm}$ (Fig.-1). Major bands were observed at $250 \mathrm{~nm}$ and $360 \mathrm{~nm}$ for the flavonoid sample (Fig.-2) also at $390 \mathrm{~nm}$ and $620 \mathrm{~nm}$ (only for Thespesia populnea) for the saponins (Fig.-3). A peak near $250 \mathrm{~nm}$ was seen in all the tannin extracts (Fig.-4). Since most of the phytochemicals are having a complex structure in which the carbon is in a specific condensation state gives us definite and unique absorption spectra mostly in the visible or UV region. ${ }^{26}$

\section{Characterization of Metabolites by FTIR spectroscopy}

The FTIR spectrum of the alkaloid sample had peaks at $2958 \mathrm{~cm}^{-1}, 1630 \mathrm{~cm}^{-1} 1,1450 \mathrm{~cm}^{-1} 1,1377 \mathrm{~cm}^{-1}$ indicative of the $\mathrm{C}-\mathrm{H}, \mathrm{C}-\mathrm{N}, \mathrm{N}-\mathrm{H}, \mathrm{N}=\mathrm{O}$ groups respectively (Fig.-5). The presence of these functional groups characterizes the metabolite as alkaloids since they are the nitrogen-containing phytocompounds. The flavonoids are poly phenolic molecules having the bands at $3400 \mathrm{~cm}^{-1}$ indicating the $\mathrm{O}-\mathrm{H}$ stretching, at $2958 \mathrm{~cm}^{-1}$ as the $\mathrm{C}-\mathrm{H}$ group and at $1631 \mathrm{~cm}^{-1}$ with the C-N group. Further peaks at $1110 \mathrm{~cm}^{-1}$ and 925 $\mathrm{cm}^{-1}$ indicate the presence of polysaccharides (Fig.-6). Saponin spectrum also has peaks at $3400 \mathrm{~cm}^{-1}$, $2929 \mathrm{~cm}^{-1} 1,1635 \mathrm{~cm}^{-1} 1,130 \mathrm{~cm}^{-1}, 997 \mathrm{~cm}^{-1}$ and $925 \mathrm{~cm}^{-1}$ which highlights the presence of O-H, C-H, moisture content, $\mathrm{C}-\mathrm{O}$ and polysaccharides (Fig.-7). Intense bands at $1130 \mathrm{~cm}^{-1}$ of O-H group, $2950 \mathrm{~cm}^{-1}$ of $\mathrm{C}-\mathrm{H}$ group, $1774 \mathrm{~cm}^{-}$of carbonyl, $1450 \mathrm{~cm}^{-1}, 1130 \mathrm{~cm}^{-1}$ of the $\mathrm{C}=\mathrm{O}$ were observed for the tannin sample (Fig.-8). ${ }^{27,28}$

\section{Characterization of Metabolites by GCMS}

The gas chromatographic analysis of the metabolites revealed the presence of many compounds of biological significance. The molecules identified are an interpretation from Dr. Dukes database on phytochemicals and they are represented with the RT and peak area. ${ }^{29}$ 
RASĀYAN J. Chem.

Vol. 12 | No. 1 |123 - 137| January - March | 2019

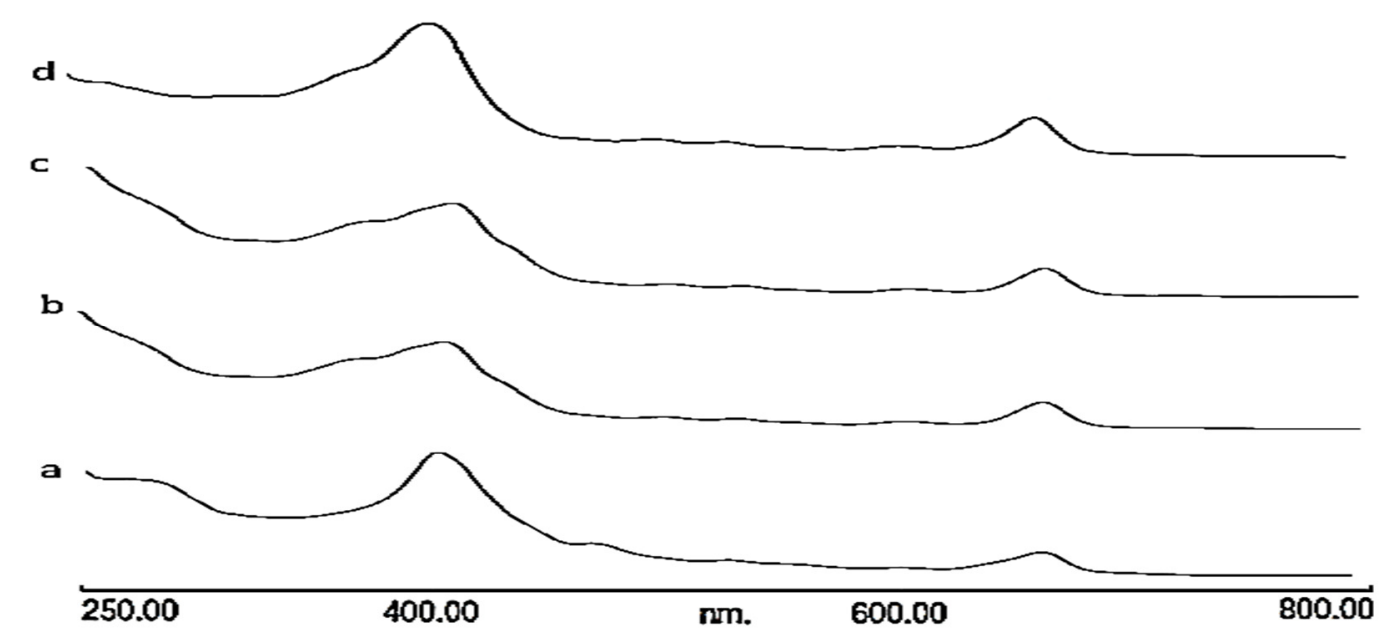

Fig.-1: UV Spectrum of Alkaloid

a-Cassia alata b- Euphorbia hirta, c- Thespesia populnea, d- Wrightia tinctoria

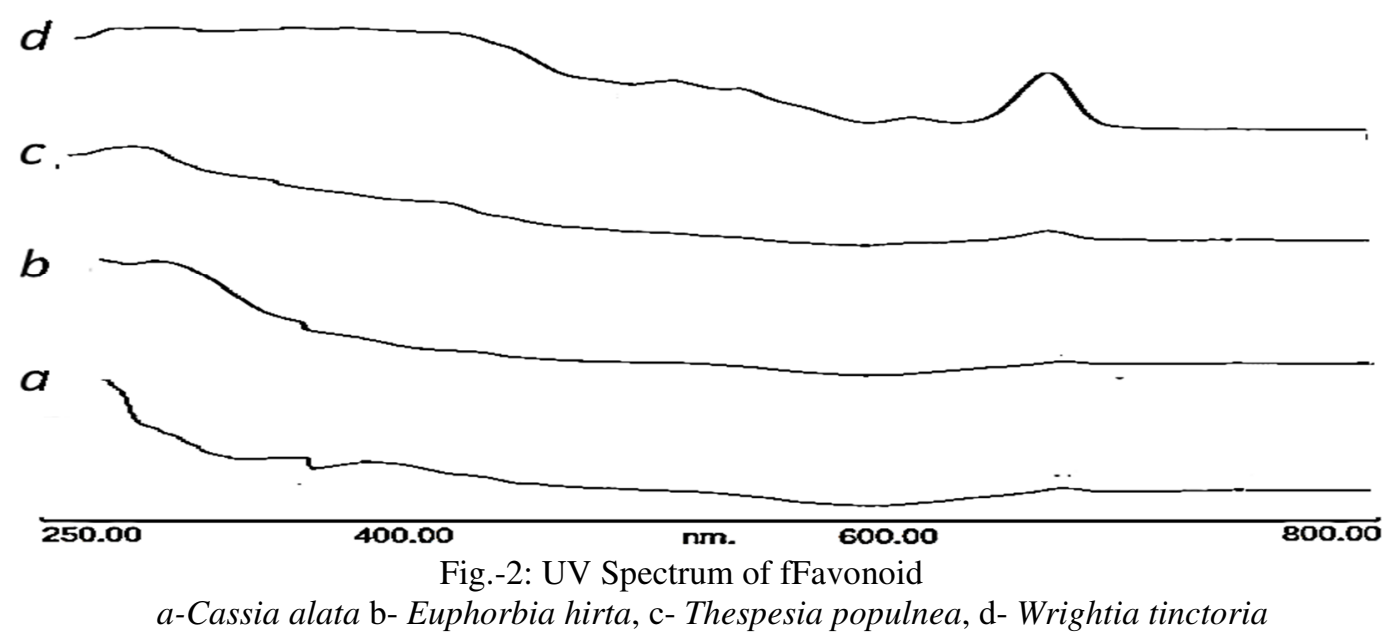

d

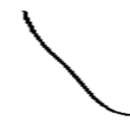

c

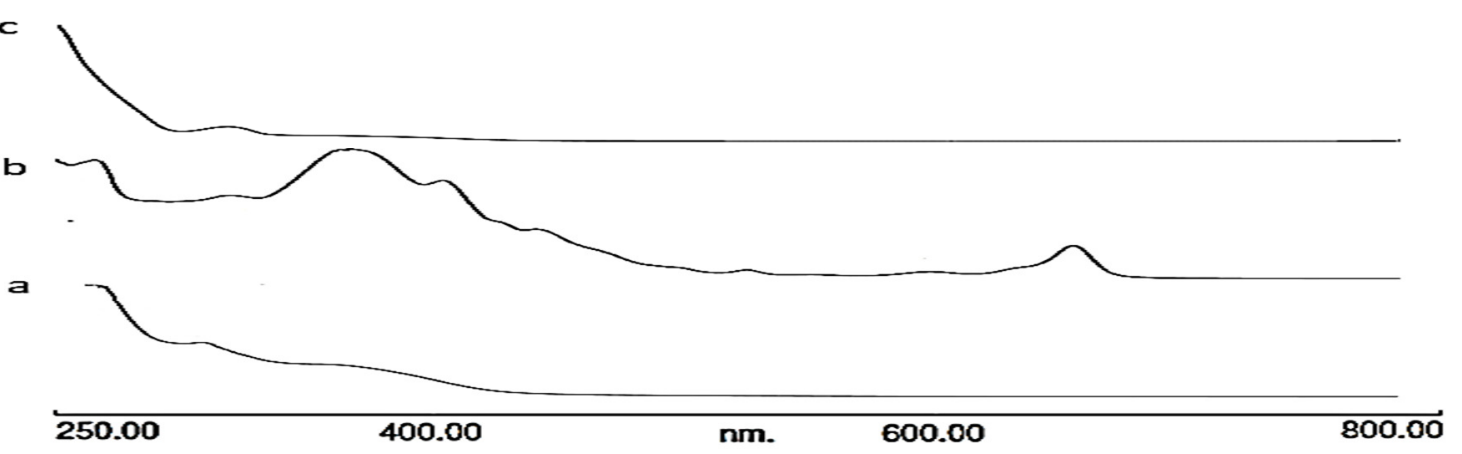

Fig.-3: UV Spectrum of Saponin a-Cassia alata b- Euphorbia hirta, c- Thespesia populnea, d- Wrightia tinctoria 
RASĀYAN $J$. Chem.

Vol. 12 | No. 1 |123 - 137| January - March | 2019

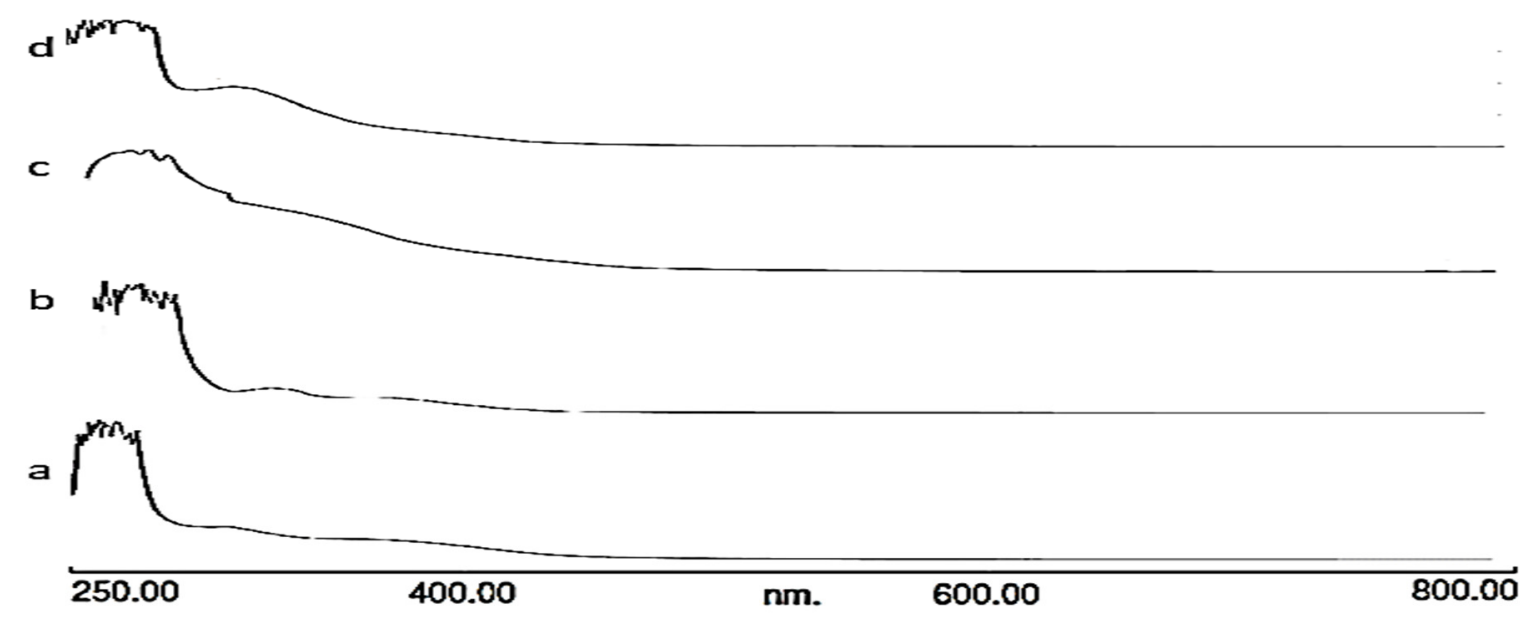

Fig.-4: UV Spectrum of Tannin

a-Cassia alata b- Euphorbia hirta, c- Thespesia populnea, d- Wrightia tinctoria

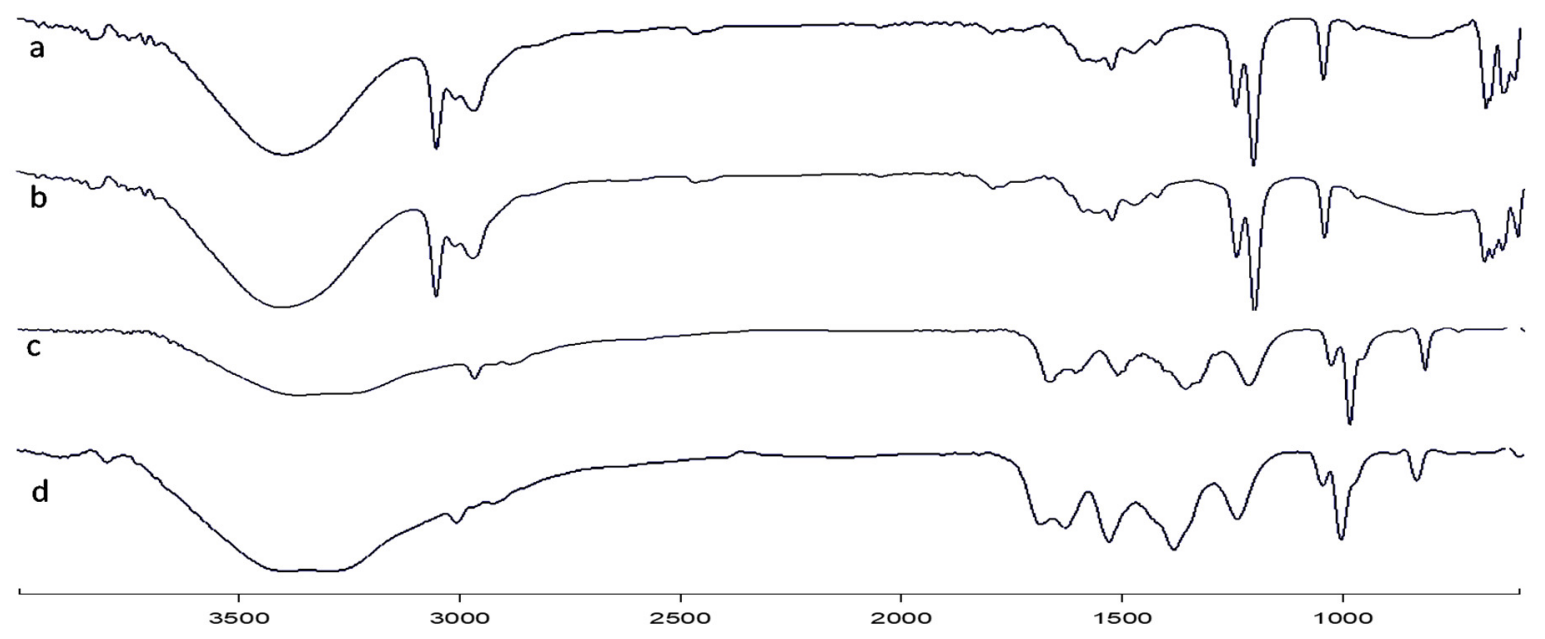

Fig.-5: FTIR of Alkaloid

a-Cassia alata b- Euphorbia hirta, c- Thespesia populnea, d- Wrightia tinctoria

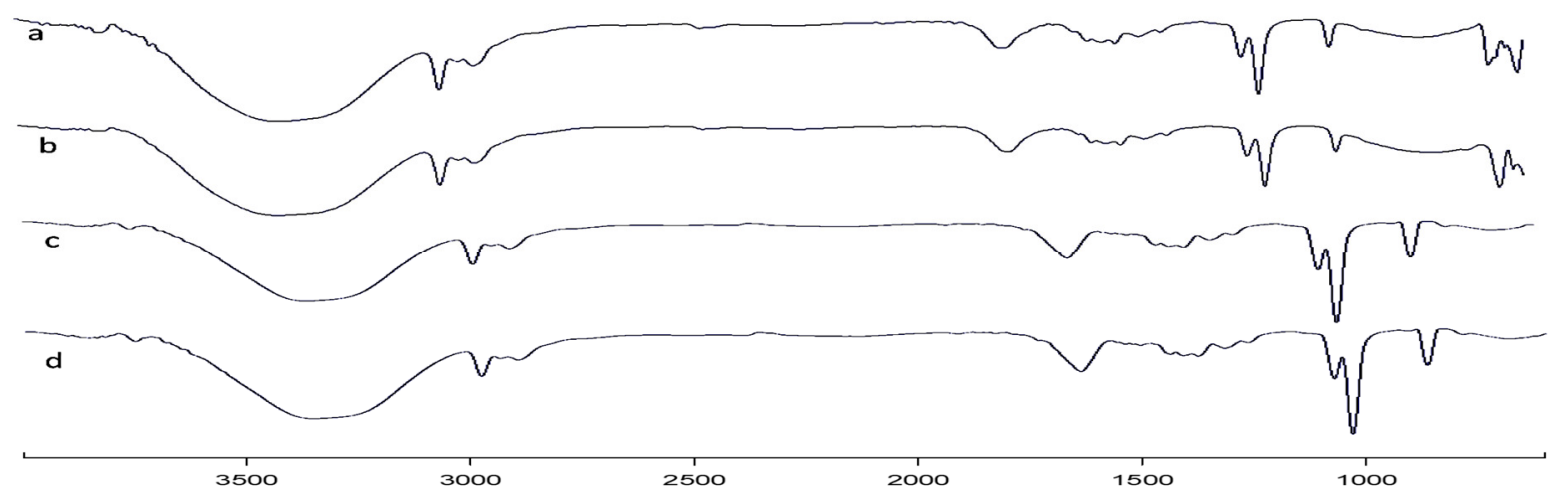

Fig.-6: FTIR of Flavonoid

a-Cassia alata b- Euphorbia hirta, c- Thespesia populnea, d- Wrightia tinctoria

\section{Alkaloids identified by GCMS}

The alkaloids and its pharmacological activity were referred from Dr. Duke's database on phytochemicals. Certain alkaloids were found to be present in all the four plants (Fig.-9) for example, 1H- 
RASĀYAN J. Chem.

Vol. 12 | No. 1 |123 - 137| January - March | 2019

Cyclopropa[3,4]benz[1,2-e] azulene-4a,5,7b,9,9a(1aH)-pentol,3- [(acetyloxy) methyl] was also found to be present in all the four plants which were reported to have Antiallergic, Anti-inflammatory, Antiseptic, Antiulcer, Antibacterial etc. Isoquinoline, 6,7-dimethoxy-1- methyl -4- (3,4- dimethylphenyl) was known to have Flavour and Perfumery activity.Phytocompounds is well known for an immunomodulatory effect like phorbol, anti tumor and cancer preventive activity like Benzeneactonitrile, alpha-[4-(dimethylamino)2,5-dimethoxyphenyl]methylene]-4-nitro were also found. Various known molecules of herbistatic and pesticidal activity was also present in the alkaloids like Furan, 2,2'-[1,2ethanediylbis(oxy)]bis[tetrahydro-5-(2-methoxy-4-methylphenyl)-5-methyl, Decanone, O-methyl oxime, Phenol, 4,4'-butylidenebis[2-(1,1-dimethylethyl)-5-methyl etc.

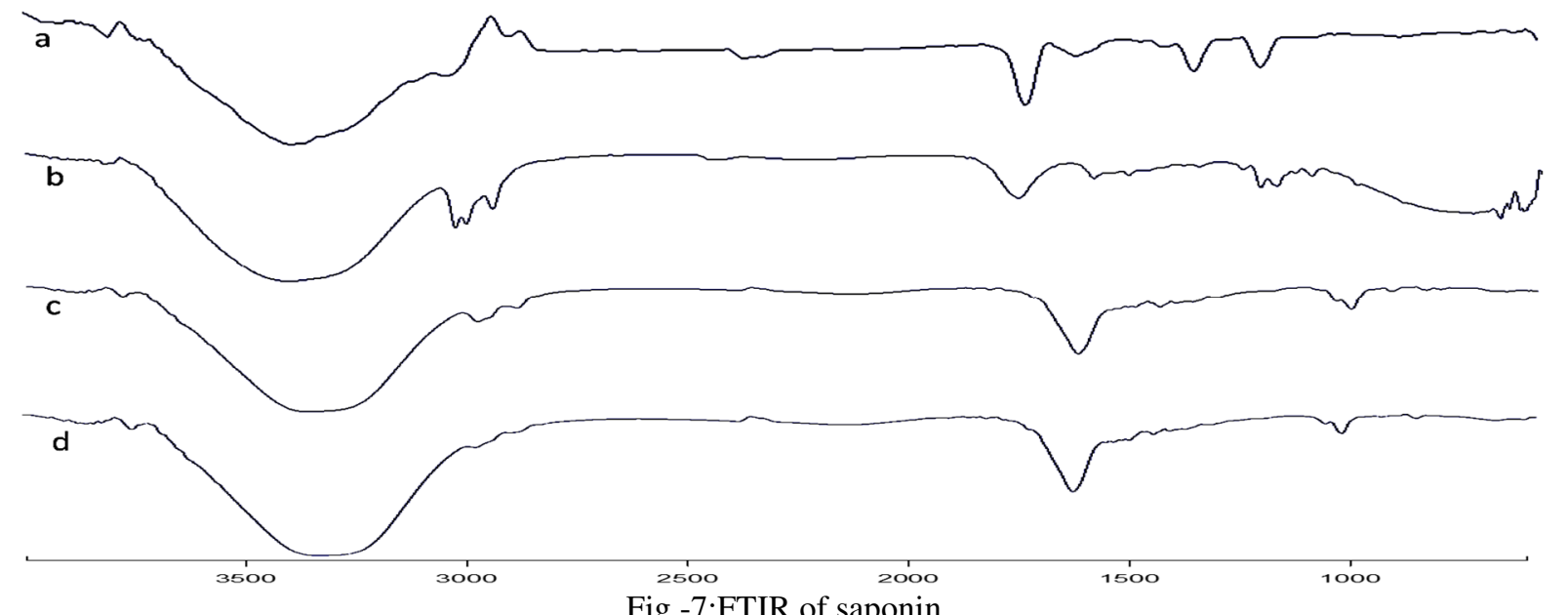

Fig.-7:FTIR of saponin

a-Cassia alata b- Euphorbia hirta, c- Thespesia populnea, d- Wrightia tinctoria

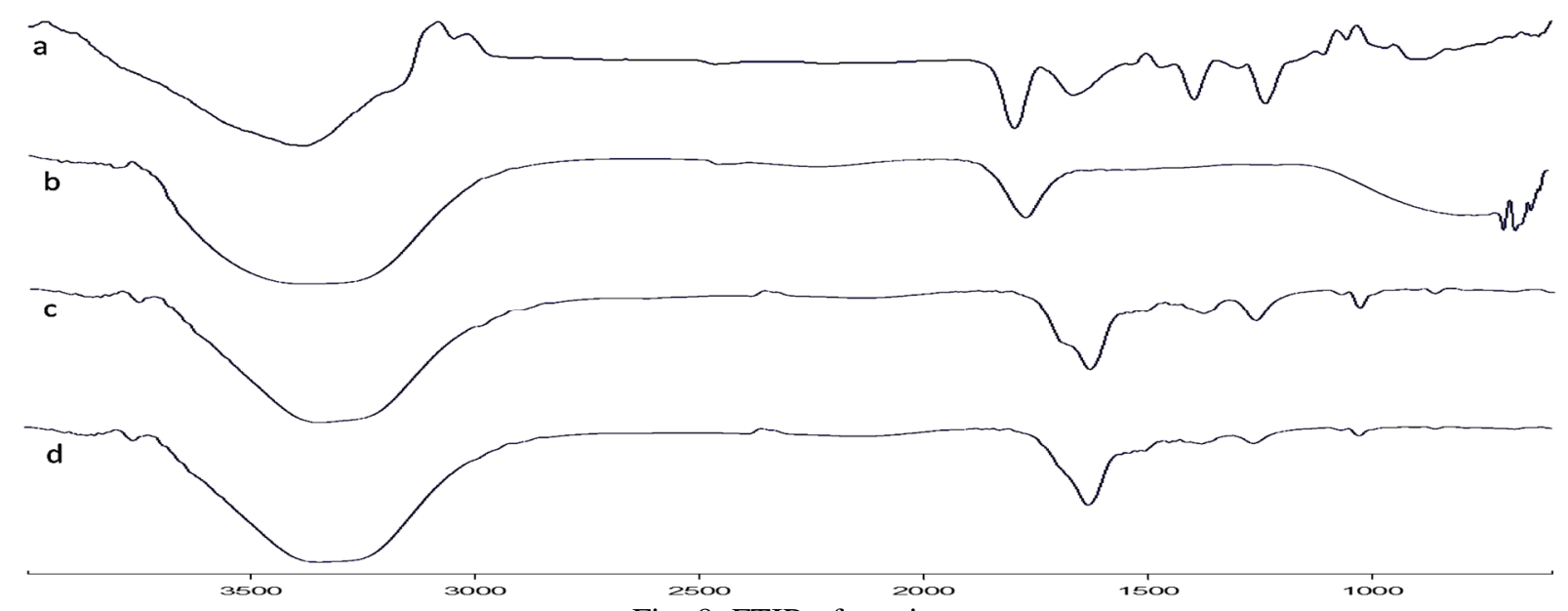

Fig.-8: FTIR of tannin

a-Cassia alata b- Euphorbia hirta, c- Thespesia populnea, d- Wrightia tinctoria

\section{Flavonoids identified by GCMS}

Euphorbia hirta has the flavonoid papavarine with retention time as 19.154 and 9.17(Fig.-10) as the peak area percentage and it is found to have Anticerebrotic, Antiedemic, Antimeasles, Antispasmodic, Antiviral, Cardiovascular, Catatonic, Cerebrovasodilator, Phosphodiesterase-Inhibitor, Anti-HIV, cAMPPhosphodiesterase-Inhibitor and Reverse-Transciptase-Inhibitor. Further the plant has formyl colchicines with RT 19.356 and peak area 8.93. This molecule has many biological activities namely AntiHIV, Antiarthritic, Antidermatitic, Antiherpetic, Antiinflammatory, Antileukemic, Antimalarial, Antimelanomic, Antimeningitic, Antimitotic, Antipsoriac, Antitumor (Breast, Colon, lung), Antivasculitic, Antibacterial, CNS-Stimulant, Cardioactive, Cassia alata has 2H-1-benzopyran-2-one, 7- 
RASĀYAN $J$. Chem.

Vol. 12 | No. 1 |123 - 137| January - March | 2019

amino-4-methyl with reported activity as Antioxidant, Antiradicular activity having RT 4.664 and peak area 10.21. Thespesia populnea has N,N'-Bis(Carbobenzyloxy)-lysine methyl(ester) with activity as Antialkalotic, Antiherpetic, Hypoargianemic is found with RT 4.436 and peak area 4.16. Another molecule Phenol, 4,4'-butylidenebis[2-(1,1-dimethylethyl)-5-methyl with RT 6.001 and peak area 9.07 as Larvicide, Fungicide, Pesticide, Phytoalexin. Wrightia tinctoriaextract were found to possess salsoline having Antihypertensive, Cardioactive, Hypotensive and phorbol having Immunostimulant, purgative, Immunosuppressant activity.

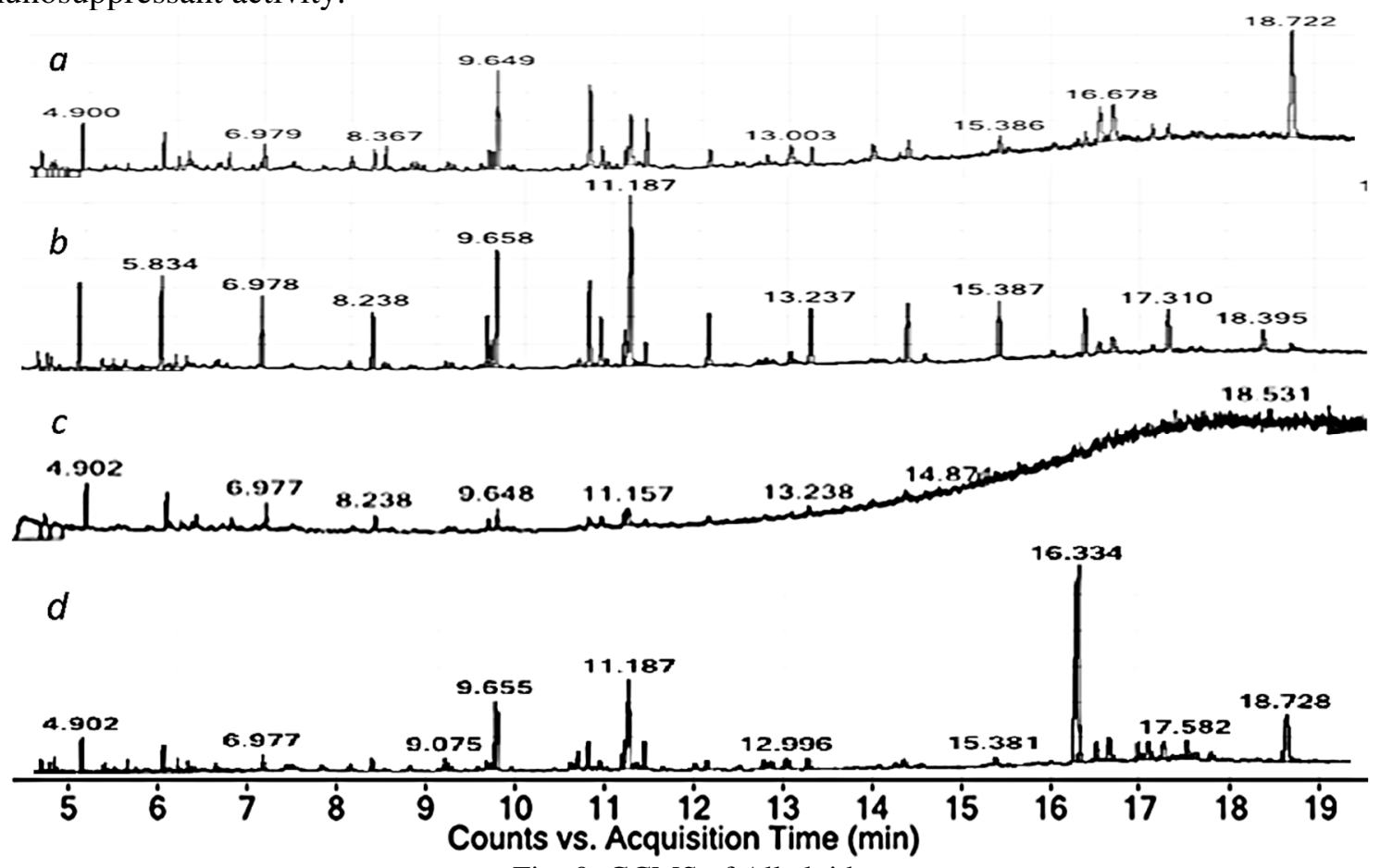

Fig.-9: GCMS of Alkaloids

a-Cassia alata ;b-Euphorbia hirta ; c-Thespesia populnea ; d-Wrightia tinctoria
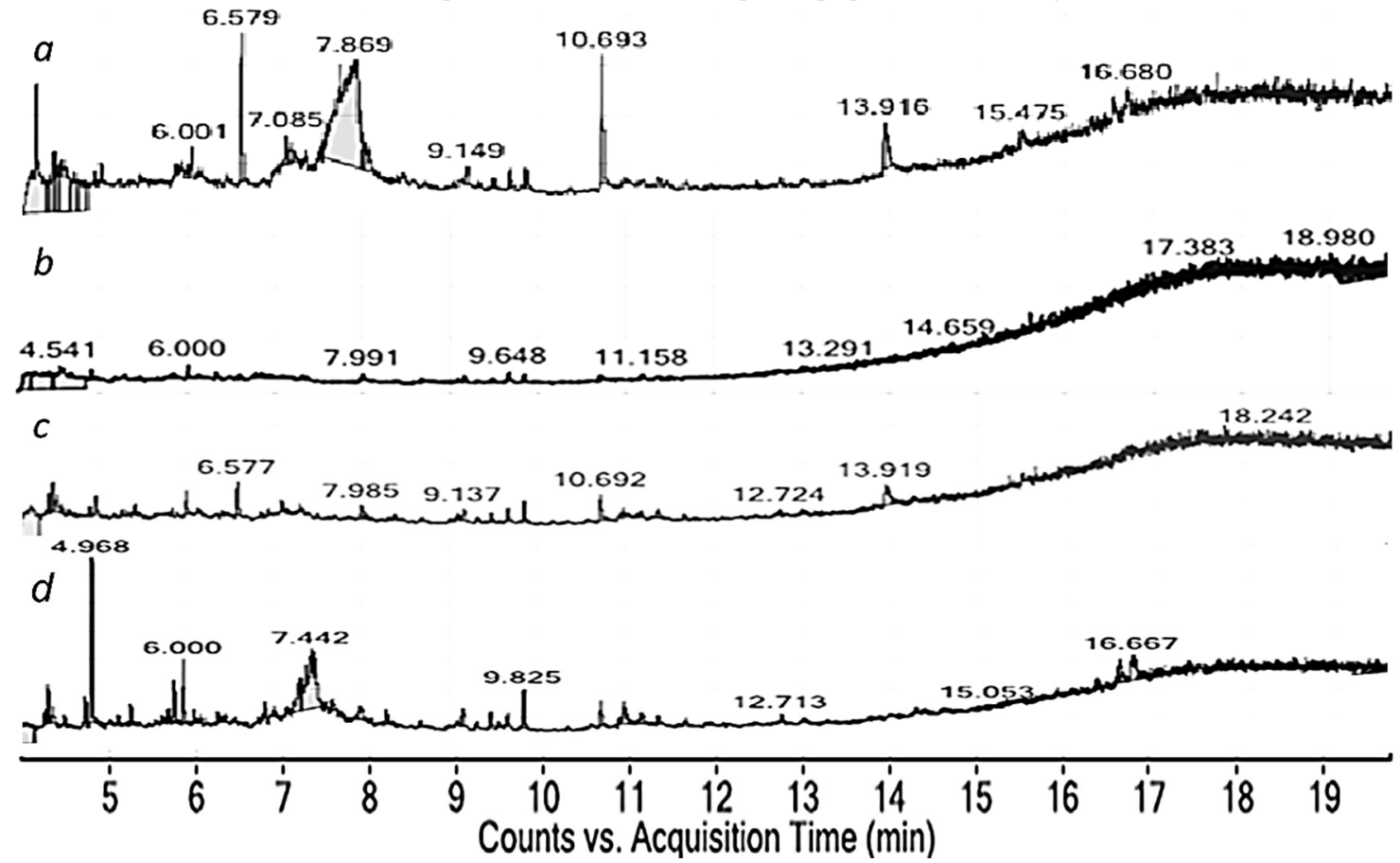

Fig.-10: GCMS of Flavonoids

a-Cassia alata ;b-Euphorbia hirta ; c-Thespesia populnea ; d-Wrightia tinctoria 

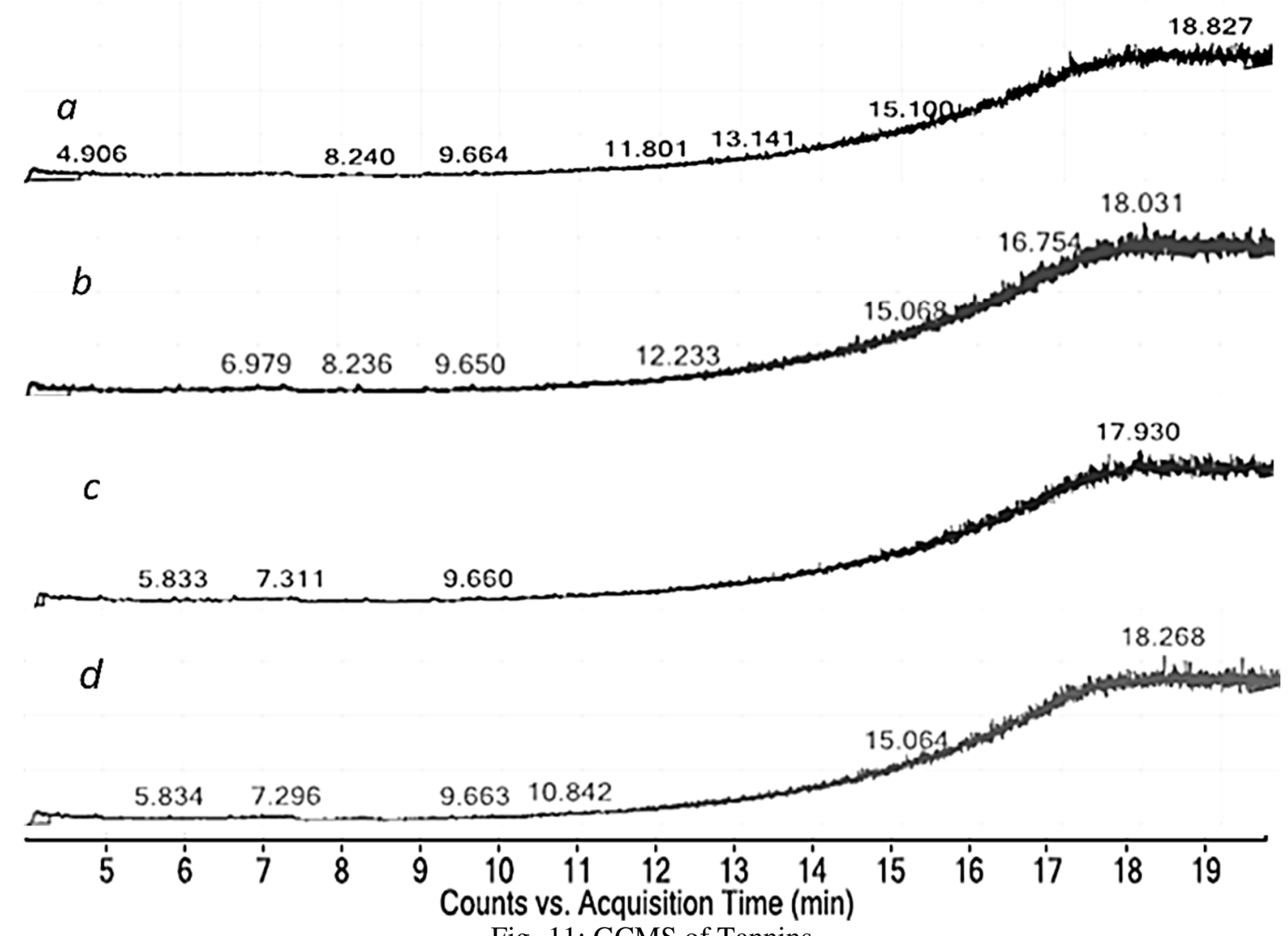

Fig.-11: GCMS of Tannins

a-Cassia alata ;b-Euphorbia hirta ; c-Thespesia populnea ; d-Wrightia tinctoria
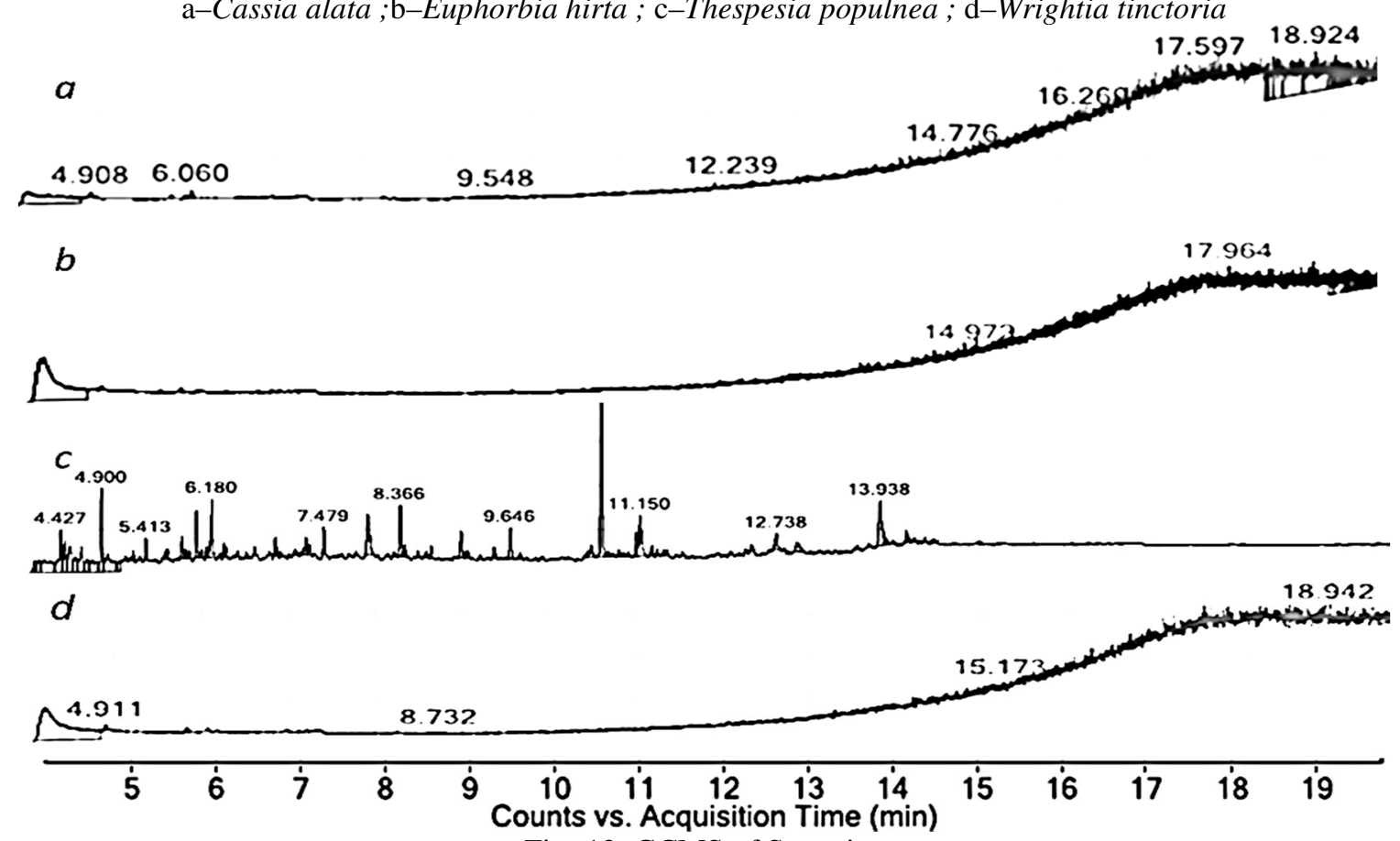

Fig.-12: GCMS of Saponins

Tannins identified by GCMS

Certain molecules like formyl colchicines and 1H-Cyclopropa[3,4]benz[1,2-e]azulene-4a,5,7b,9,9a(1aH)pentol, 3-[(acetyloxy)methyl with already mentioned activity is found in all the four plants (Fig.-11). Papaverine was found in Cassia alata and Thespesia populnea. Spiro[isoquinoline-1,2'indene $] 8,1,2,3,4,2^{\prime}, 3^{\prime}$ '-tetrahydro-6'-hydroxy-6,7,3',7'-tetramethoxy-2- which is a molecule for Flavour 
and Perfumery was present Euphorbia hirta and Wrightia tinctoria. Another molecule that was found in Thespesia populnea and Wrightia tinctoria is Oxazolo[4,3-a]isoquinolin-3-one, 1,5,6,10b-tetrahydro-8,9tetrahydro-8,9-dimethoxy-1,10b-dimethyl-1-(3-p with RT as 18.569 and 19.598 having peak area 4.29 and 14.97 respectively(Fig.-11). Hydroxymethyl colchicine was also found in them.

\section{Saponins identified by GCMS}

The compound 6-Methoxy-4-methylquinoline-2-thiol with RT 19.309 and peak area as 2.9 was identified in Euphorbia hirta and Cassia alata(Fig.-12)and they are found to have Antileishmanic, Antimalarial, Preservative, Pesticide activity. Cassia alata had Isoquinoline, 6,7-dimethoxy-1- methyl -4- (3,4dimethylphenyl), Oxazolo[4,3-a]isoquinolin-3-one, 1,5,6,10b-tetrahydro-8,9-tetrahydro-8,9-dimethoxy1,10b-dimethyl-1-(3-p and Pyrano[3,4,5-i,j]quinolizin-1,8(3H)-dione, 9-acetyl-3a,4,5,6-tetrahydro-3-(2pyridyl) with $18.418,18.924,19.141$ as RT and $28.11,97.12,4.49$ as their respective peak area. Thespesia populnea had many metabolites present namely Carda-4,20(22)-dienolide, 3-[(6-deoxy-3-Omethyl-alpha-D-allopyranosyl)oxy]-1,14-dihydr with 4.427 as the RT and 47.71 as the peak area having Antithrombotic, Antiseptic, Antitumor, Cyclooxygenase- inhibitor, Irritant, Lipoxygenase- Inhibitor, pesticide activity. 3-Methoxymethoxy-3,7,16,20-tetramethyl-heneicosa-1,7,11,15,19-pentaene possessing the insecticide and pesticide activity. 3-Pyridinecarbonitrile, 4-(methoxymethyl)-6-methyl-2-(2propenyloxy) was also found in the extract which is having the CNS depressant, Flavor and Irritant activity. Benzene, 3-[3-iodo-2-(iodomethyl)-2-methylpropyl]-1,2,4,5-tetramethyl with antitumor and cancer preventive activity.

\section{Separation of Compounds from Metabolite by Thin Layer Chromatography}

The alkaloids, flavonoids, tannins and saponins extracted from the four plants were characterized by thin layer chromatography and the compounds were confirmed by visualizing in electromagnetic radiations under the visible and ultra violet range (Fig.-13 to 16). The Rf value of the separated compounds are labelled on the figure itself. Component with Rf value of 0.30 in alkaloids extraction of $C$. alata could be visualized on exposure to UV light (Fig.-13). Likewise in flavonoid extraction of Thespesia populnea and Wrightia tinctoria, some components were visualized (Fig.-14). Sonam et $\mathrm{al}^{30}$ found alkaloids, flavonoids, tannins and phenols by spraying the TLC separated plate with appropriate solvents.
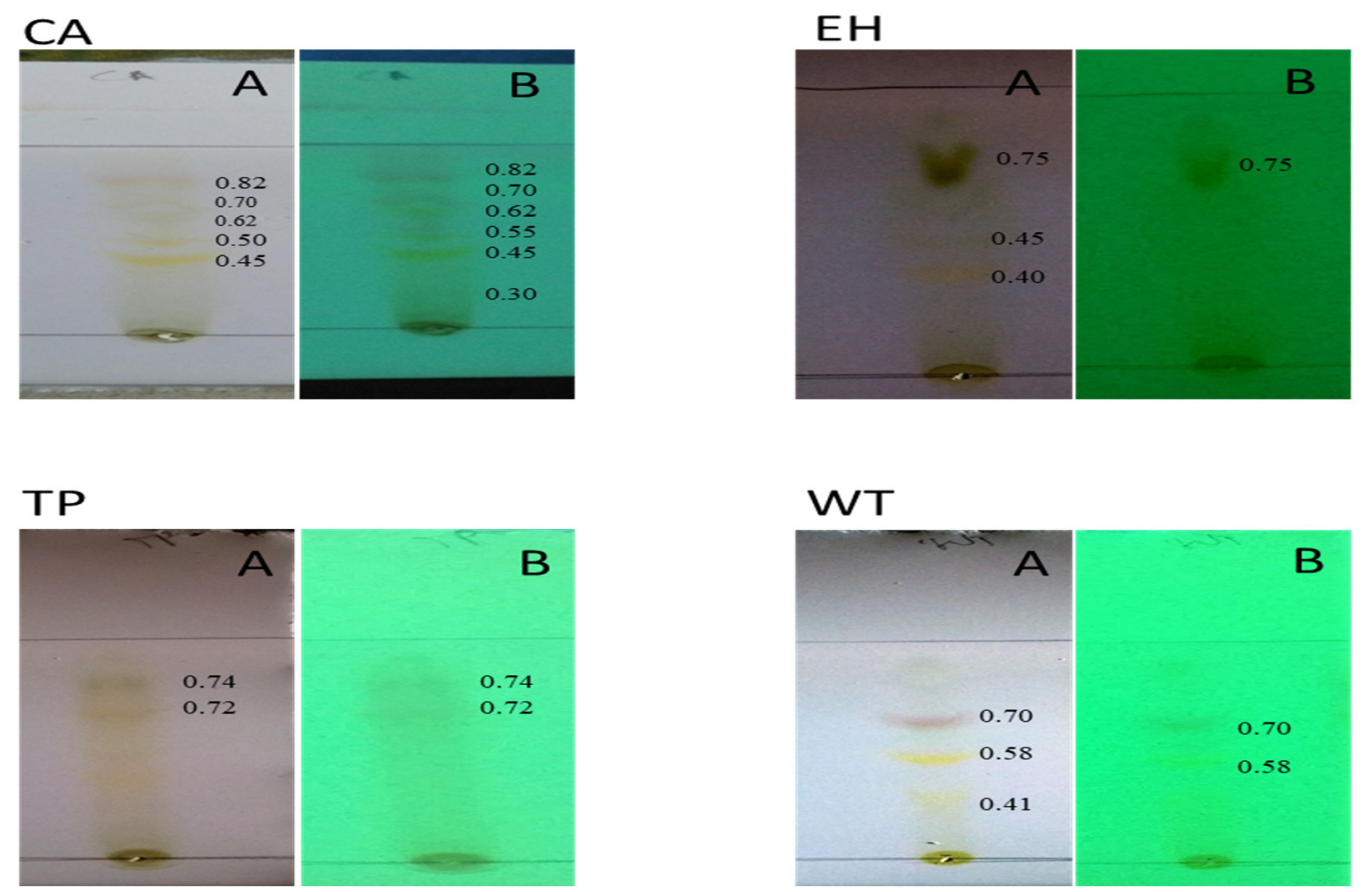

Fig.-13: Thin Layer Chromatogram of Alkaloids A - Visible Light, B- UV Light

CA-Cassia alata, EH - Euphorbia hirta, TP- Thespesia populnea, WT - Wrightia tinctoria 
RASĀYAN J. Chem.

Vol. 12 | No. 1 |123 - 137| January - March | 2019

CA

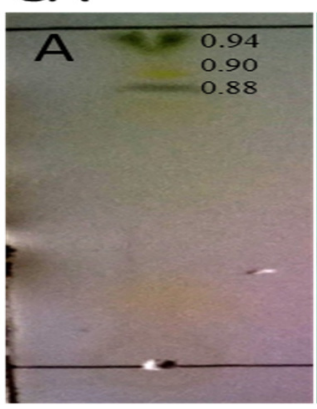

TP

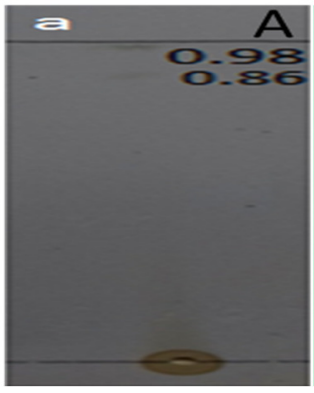
A - Visible Light, B- UV Light

CA-Cassia alata, EH - Euphorbia hirta, TP- Thespesia populnea, WT - Wrightia tinctoria

CA

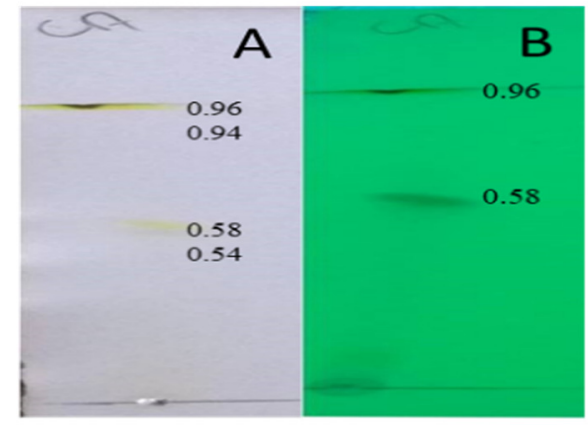

TP

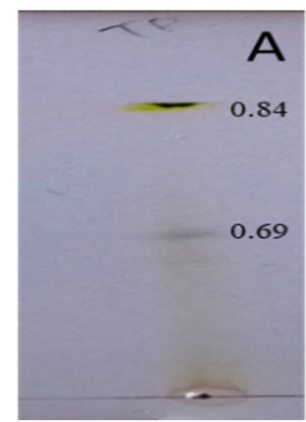

B

0.69

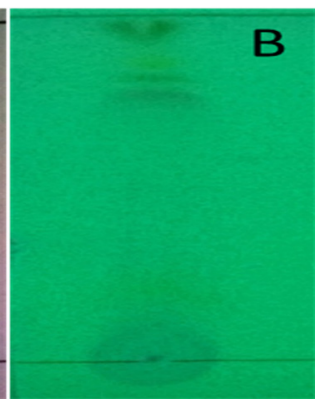

Fig.-14: Thin Layer Chromatogram of Flavonoids

\section{$\mathrm{EH}$}

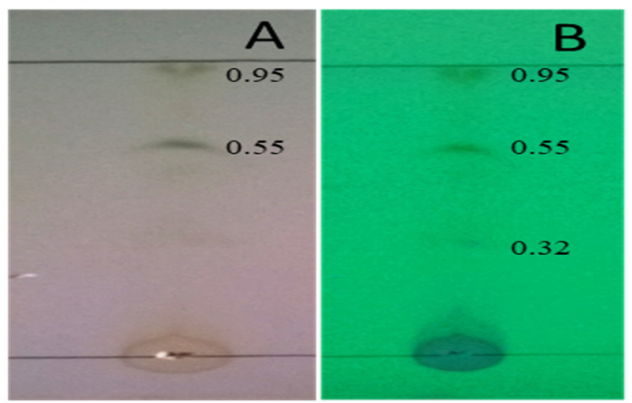

WT

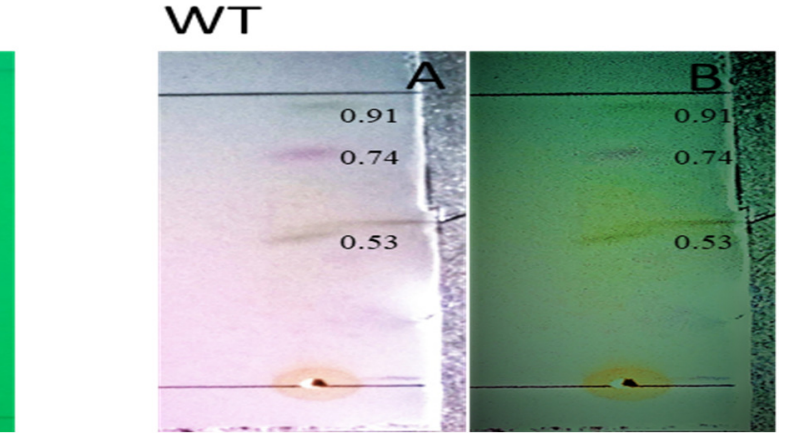

B

0.58
0.53

0.53

\section{$\mathrm{EH}$}

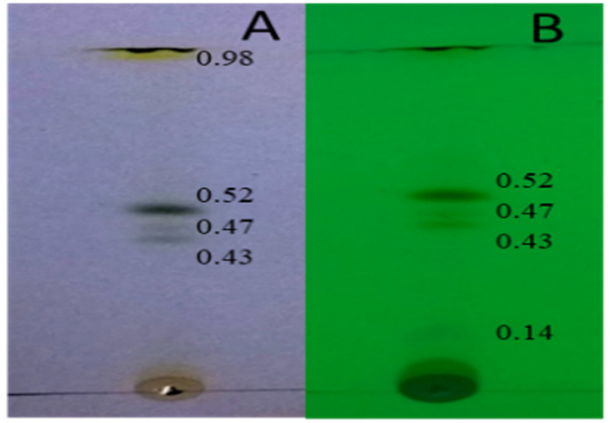

WT
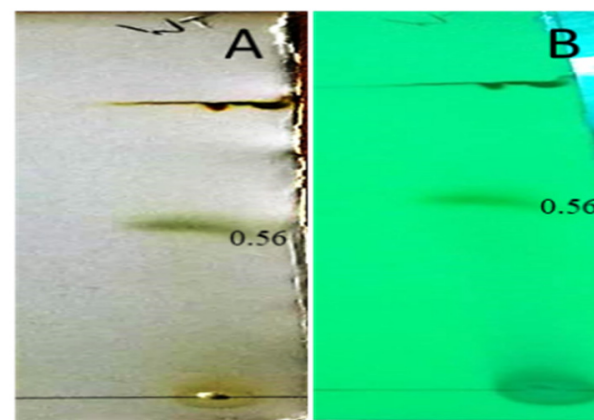

Fig.-15: Thin Layer Chromatogram of Saponins

A - Visible Light, B- UV Light

CA-Cassia alata, EH - Euphorbia hirta, TP- Thespesia populnea, WT - Wrightia tinctoria 
RASĀYAN $J$. Chem.

Vol. 12 | No. 1 |123 - 137| January - March | 2019
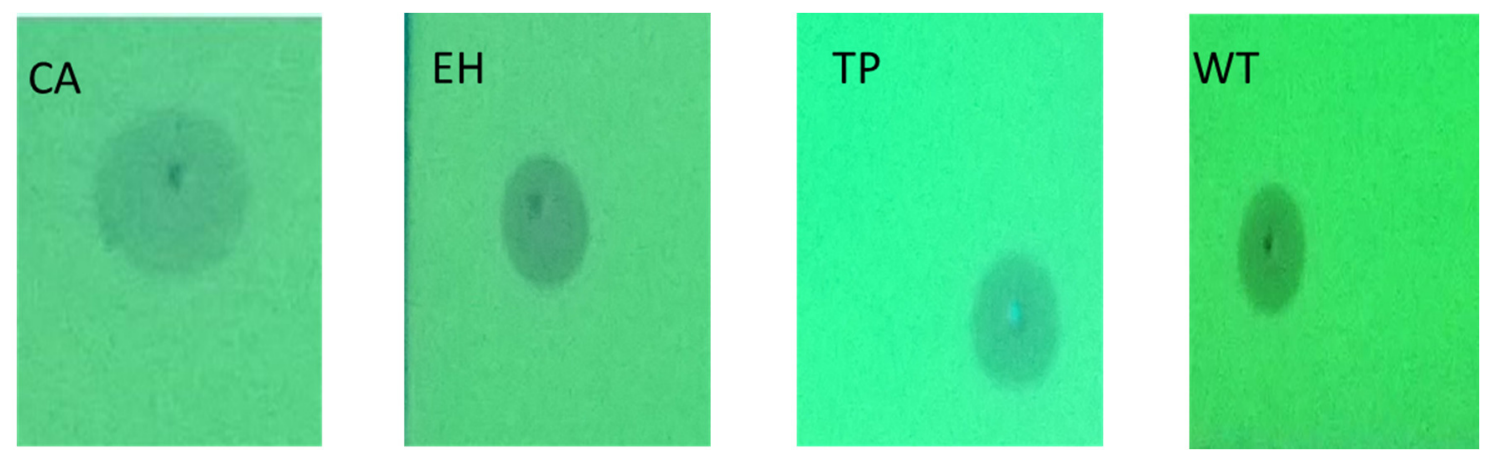

Fig.-16: Thin Layer Chromatogram of Tannins under UV Light

CA-Cassia alata, EH - Euphorbia hirta, TP- Thespesia populnea, WT - Wrightia tinctoria

\section{Invitro Antibacterial Activity}

Agar Well Diffusion Method

All the extracted metabolites were tested for the antibacterial activity for the working concentration $2 \mu \mathrm{g}$, $4 \mu \mathrm{g}, 8 \mu \mathrm{g}$ and $16 \mu \mathrm{g}$ (Table-1) which showed an increase in activity with the corresponding increase in the dose. The alkaloids and saponins of all the four plants taken for the study had notable results against all working concentrations. The highest of $1.9 \mathrm{~cm}$ of was observed for $16 \mu \mathrm{g}$ concentration ofWrightia tinctoria and saponin of Euphorbia hirta. Tannin of Euphorbia hirta, Thespesia populnea and alkaloid of Thespesia populnea had the zone of inhibition of $1.7 \mathrm{~cm}$ at $16 \mu \mathrm{g}$. The tannin of Cassia alataand flavonoid of Thespesia populneadid not show any activity. Karou et $\mathrm{a}^{31}$ also have reported the alkaloids cryptolepine and quindoline to have antibacterial activity. The flavonoids were found not only to have antimicrobial activity but also found to interfere with the secretion of an inflammatory mediator and ciliotoxin pyocyanin from respiratory isolates of $P$. aeruginosa. ${ }^{32}$

Table-1: Antibacterial Activity of the Metabolites by Agar Well Diffusion

\begin{tabular}{|c|c|c|c|c|}
\hline Concentration $(\mu \mathrm{g})$ & C. alata & E.hirta & T.populnea & W.tinctoria \\
\hline \multicolumn{5}{|c|}{ Alkaloid } \\
\hline 2 & 0.3 & 0.1 & 0.4 & 0.3 \\
\hline 4 & 0.5 & 0.2 & 0.8 & 0.5 \\
\hline 8 & 0.9 & 0.4 & 1.4 & 0.7 \\
\hline 16 & 1.2 & 0.5 & 1.7 & 0.9 \\
\hline \multicolumn{5}{|c|}{ Flavonoid } \\
\hline 2 & -ve & 0.2 & -ve & 0.2 \\
\hline 4 & 0.6 & 0.4 & -ve & 0.4 \\
\hline 8 & 0.8 & 0.6 & -ve & 0.6 \\
\hline 16 & 1.0 & 1.0 & -ve & 0.9 \\
\hline \multicolumn{5}{|c|}{ Saponin } \\
\hline 2 & 0.1 & 0.8 & 0.3 & 0.6 \\
\hline 4 & 0.3 & 0.9 & 0.4 & 0.8 \\
\hline 8 & 0.5 & 1.6 & 0.8 & 1.3 \\
\hline 16 & 1.0 & 1.9 & 0.7 & 1.5 \\
\hline \multicolumn{5}{|c|}{ Tannin } \\
\hline 2 & -ve & 0.5 & 0.8 & 0.8 \\
\hline 4 & -ve & 0.8 & 1.0 & 1.0 \\
\hline 8 & -ve & 1.4 & 1.6 & 1.4 \\
\hline 16 & -ve & 1.7 & 1.7 & 1.9 \\
\hline
\end{tabular}

-ve - negative 


\section{RASĀYAN J. Chem.}

Vol. 12 | No. 1 |123 - 137| January - March | 2019

\section{Swarming Motility Assay of Pseudomonas aeruginosa for the Metabolites}

The ability of the phytochemicals to inhibit the movement of the organisms was tested by the swarming motility assay (Fig.-17). Plate with DMSO was used as the negative control. Alkaloid and tannin of Cassia alata and saponin of Wrightia tinctoria were inhibiting the motility of Pseudomonas aeruginosa.

\section{ALKALOIDS}
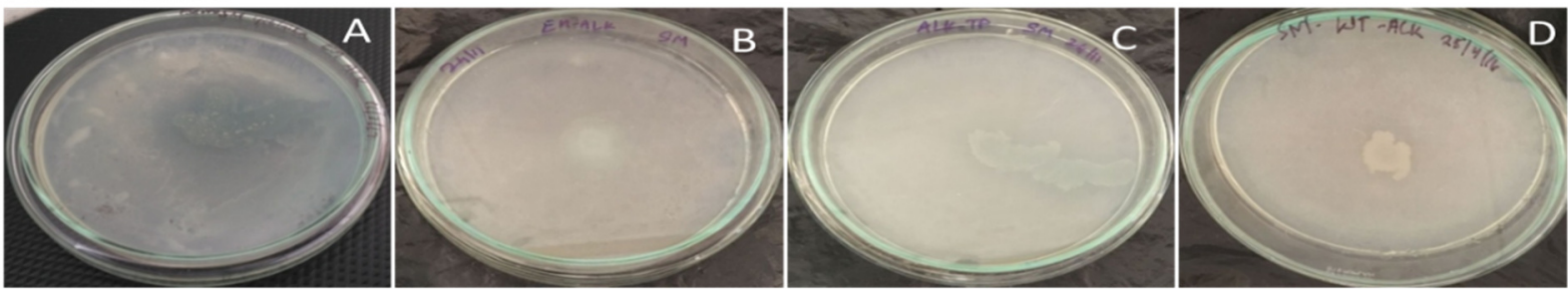

\section{FLAVONOIDS}
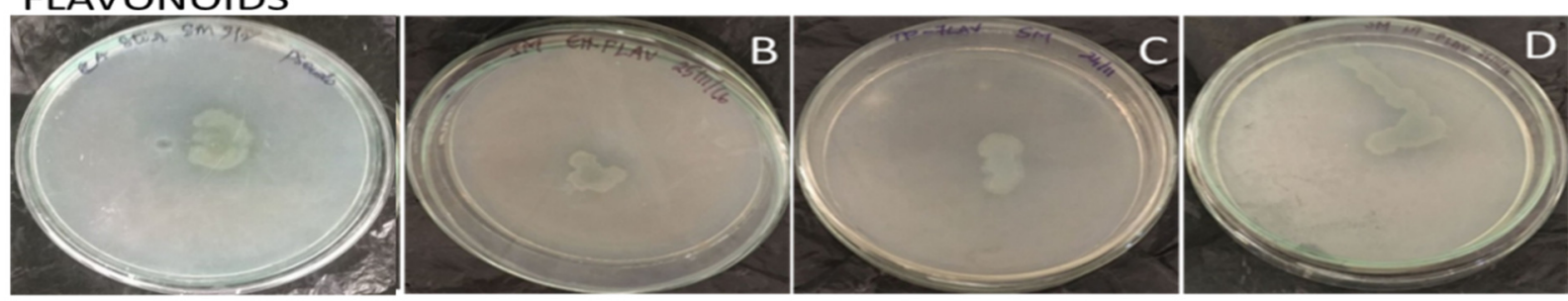

\section{SAPONINS}

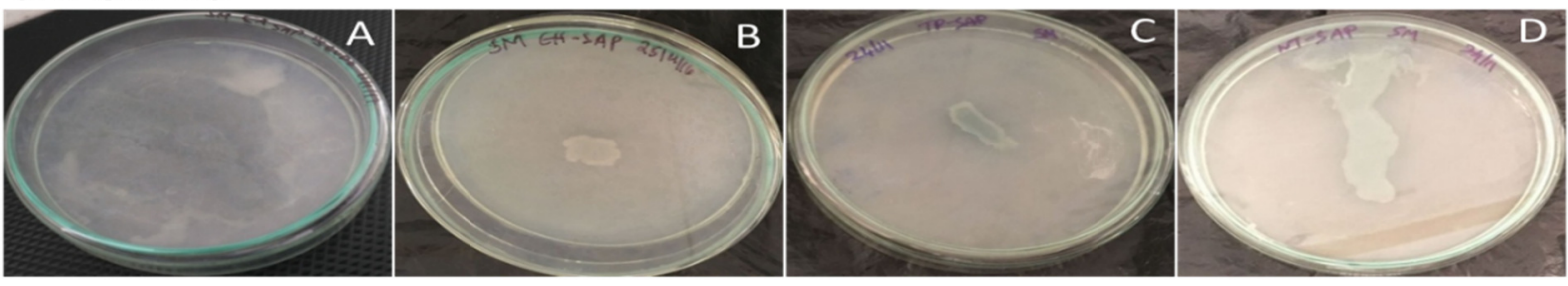

\section{TANNINS}
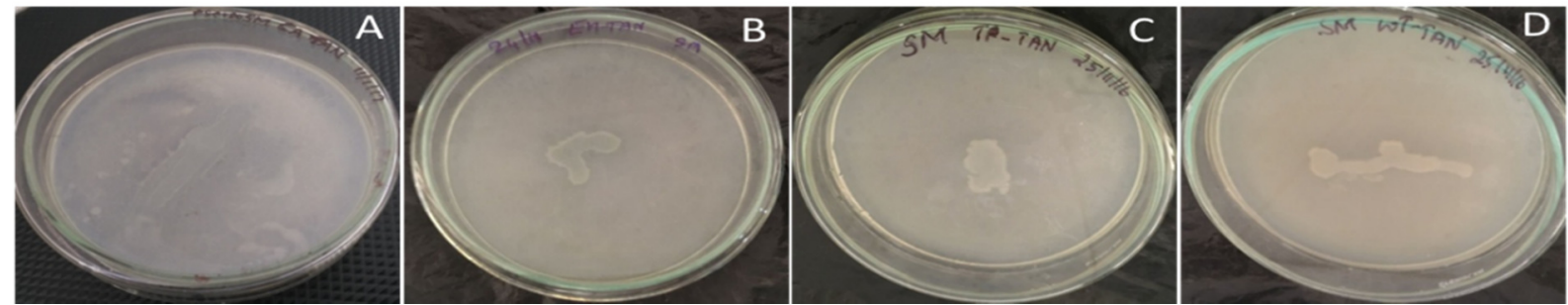

Fig.-17:Swarming Motility Assay of the Metabolites

A- Cassia alata B- Euphorbia hirta, C- Thespesia populnea, D- Wrightia tinctoria
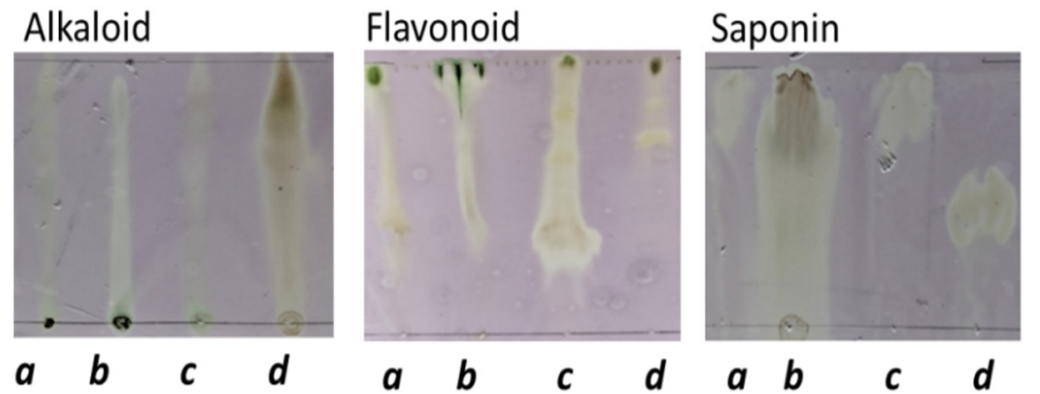

\section{Tannin}

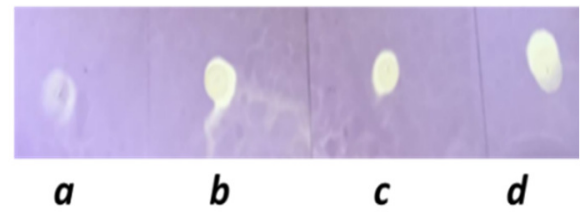

Fig.-18: TLC Bioautography for Antioxidant Activity of Metabolites a-Cassia alata b- Euphorbia hirta, c- Thespesia populnea, d- Wrightia tinctoria 
RASĀYAN $J$. Chem.

Vol. 12 | No. 1 |123 - 137| January - March | 2019

Tannin Alone was done as Spot Assay on TLC Plate

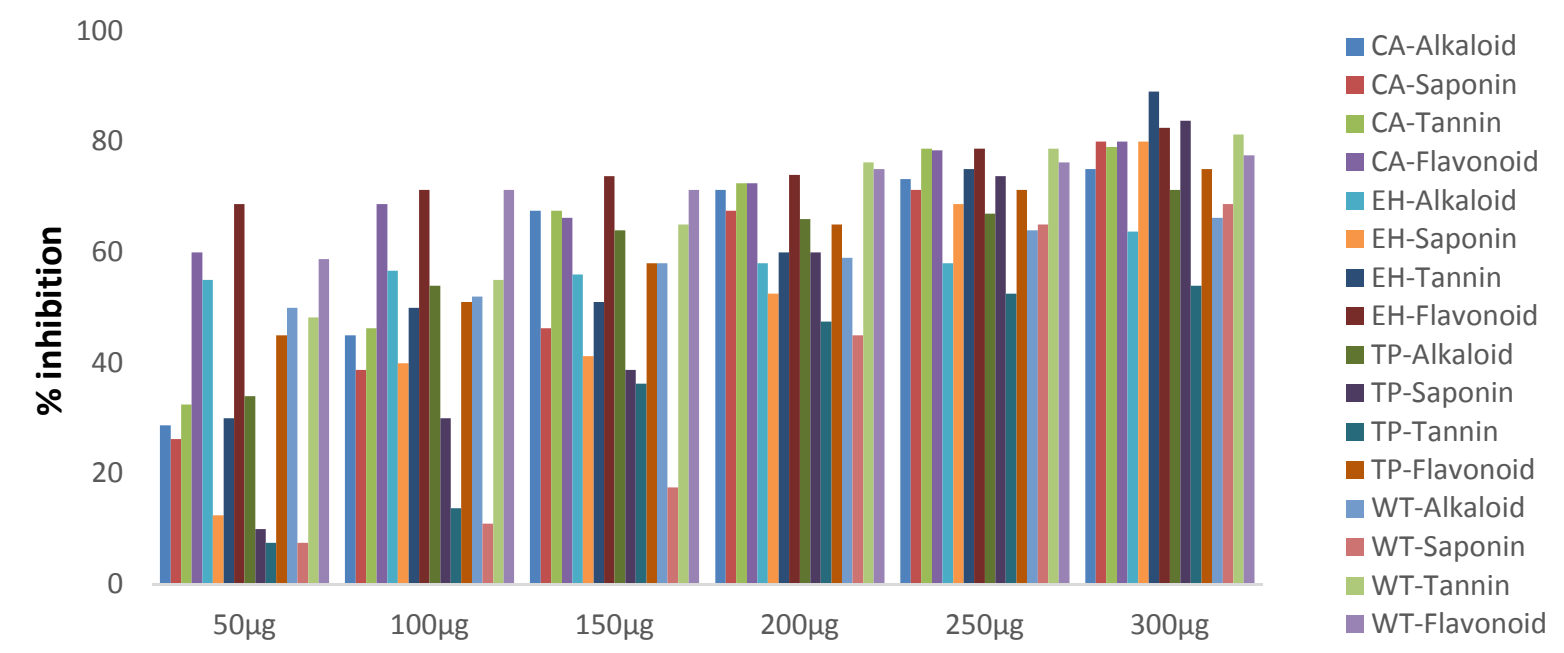

Fig.-19: Antioxidant Activity of Metabolites of all Plants chosen in this Study using DPPH Assay

TP-Thespesia populnea, WT-Wrightia tinctoria, CA-Cassia alata, EH-Euphorbia hirta

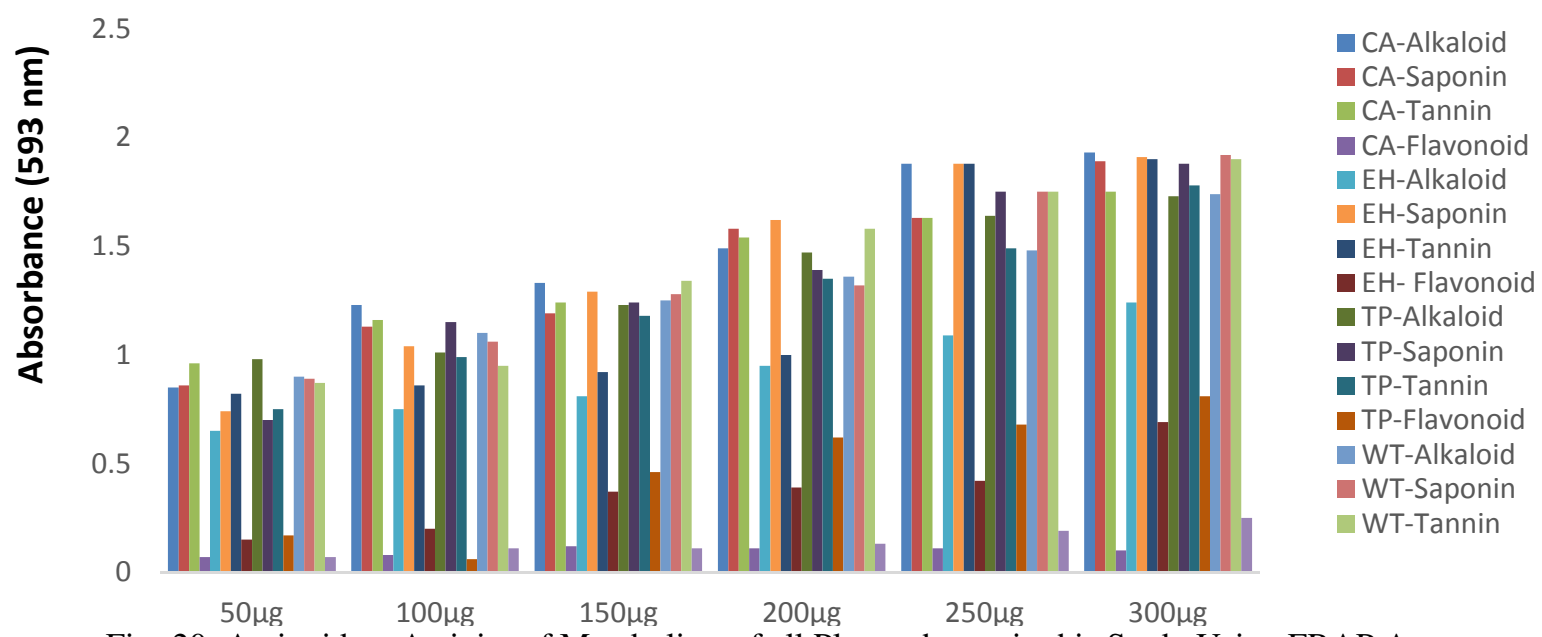

Fig.-20: Antioxidant Activity of Metabolites of all Plants chosen in this Study Using FRAP Assay

TP-Thespesia populnea, WT-Wrightia tinctoria, CA-Cassia alata, EH-Euphorbia hirta

\section{Invitro Antioxidant Activity}

\section{In-vitro Antioxidant Activity by TLC Bioautography}

There are several studies to support TLC bioautography analysis for identifying antioxidant molecules. ${ }^{21,33}$ Antioxidant activity for the metabolites was checked through TLC bioautography (Fig.18). All the metabolites were showing antioxidant activity on TLC plate. Thus, it was subjected to further qualitative antioxidant activity analysis.

\section{Antioxidant Assay for the Metabolites}

DPPH scavenging activity was found to be better for the metabolites (Fig.-19 to 21). Plant metabolites especially phenolic groups have low bond dissociation energies due to the presence of $\mathrm{OH}$ groups where the hydrogen atom is easily removed by the free radical supporting the first mechanism. ${ }^{34}$

The highest free radical scavenging activity was found for tannins of Euphorbia hirta of $88.75 \%$, saponin of Thespesis populnea of $83.75 \%$, tannin of Wrightia tinctoria of $81.25 \%$, saponin of Euphorbia hirta and Cassia alata of $80 \%$ at $50 \mu \mathrm{g}$ concentration. Flavonoids in particular of Euphorbia hirta, Wrightia tinctoria and Cassia alata was observed to have good percentage scavenging activity for all the concentrations. The antioxidant activity was also investigated by FRAP assay and phosphomolybdenum assay for the plant metabolites. The FRAP assay, in particular, takes count of the reduction possibility of 
an antioxidant molecule at a given concentration by converting the ferric complex to a ferrous moiety discharging a colored reaction by a transfer of a hydrogen atom at a lower $\mathrm{pH}$.

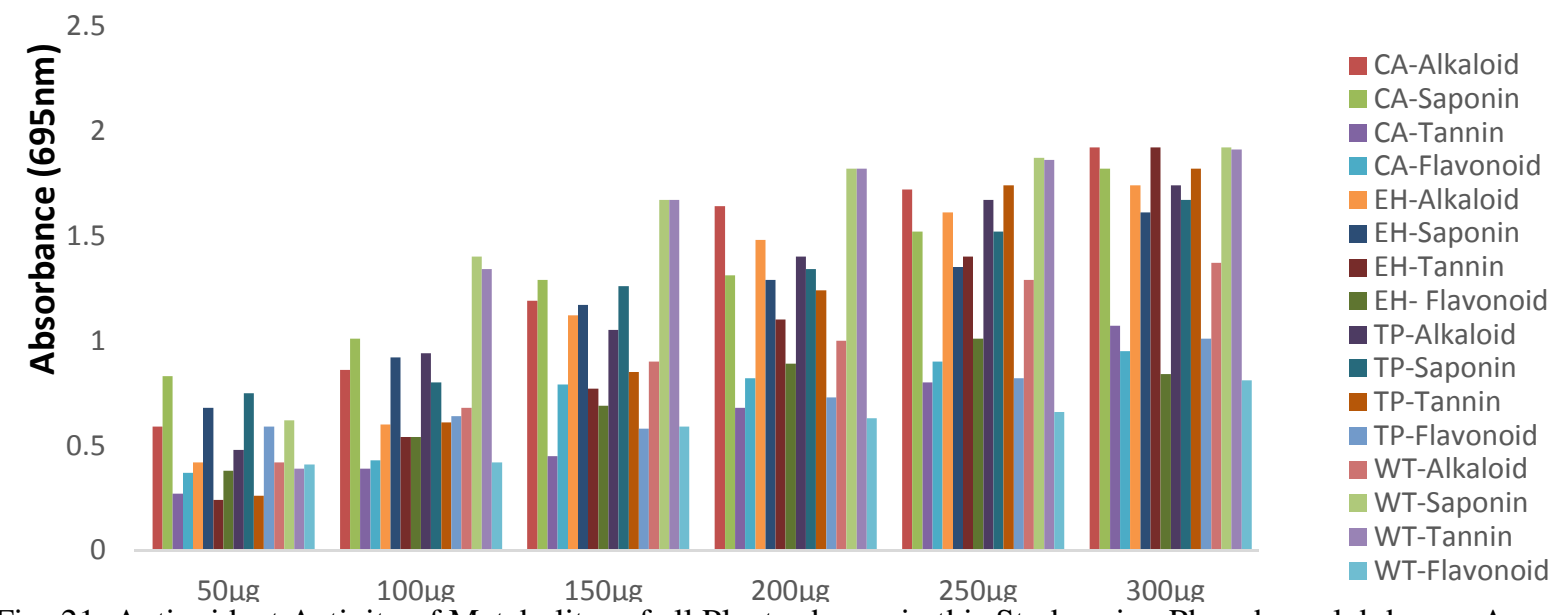

Fig.-21: Antioxidant Activity of Metabolites of all Plants chosen in this Study using Phosphomolybdenum Assay TP-Thespesia populnea, WT- Wrightia tinctoria, CA-Cassia alata, EH-Euphorbia hirta

The change in color is measured at $593 \mathrm{~nm}$. The metabolites of all the plants chosen in the study showed dose dependent activity (Fig.-20 and 21). The response of the metabolites for this behavior could be understood by their altered mechanism in the antioxidant activity. AReducing potential may depend on their ability to ionize the molecules. ${ }^{35}$ Lower ionization potential brings about easier electron abstraction. In this regard considering both the mechanism of bond dissociation energies and ionization potential could bring about the best antioxidant molecules combating degenerative disorders brought about by the oxidative stress damage of the cells. At $200 \mu \mathrm{g}$ concentration all the metabolites had $50 \%$ inhibition while flavonoids had better inhibition even at lesser concentrations most certainly from the polyphenolic groups. We believe phytochemicals being the most interesting molecules with structural complexities having many functional groups in different conformation could serve us the best antioxidants. Further studies into the structure activity relationships should be undertaken to understand the sole energy producers our Nature's gift, 'Plants'.

\section{CONCLUSION}

In this study, Cassia alata, Thespesia populnea, Euphorbia hirta and Wrightia tinctoria were collected and subjected for extraction of different metabolites viz. alkaloids, tannins, saponin and flavonoids. All the metabolites of Cassia alata were found to possess antibacterial and antioxidant activity. Metabolites from all the plants were exhibiting antioxidant activity, which was evaluated by qualitatively by TLC chromatography and quantitatively by DPPH assay and phosphomolybdenum assay.

\section{ACKNOWLEDGEMENT}

All the authors acknowledge the support rendered by Sathyabama Institute of Science and Technology.

\section{REFERENCES}

1. D. O. Kennedy, E. L. Wightman, Advances in Nutrition, 2(1), 32(2017), DOI: 10.3945/an.110.000117

2. M. Wink, 2010, Annual Plant Reviews, In: Biochemistry of Plant Secondary Metabolites, Second Edition, Wiley Blackwell Publication, p 40.

3. M. M. Cowan, Clinical Microbiology Reviews, 12(4), 564(1999).

4. M. Saxena, J. Saxena, R. Nema, D. Singh, A. Gupta, Journal of Pharmacognosy and Phytochemistry,1(6), 168(2013).

5. B.H. Havsteen, Pharmacol. Ther., 96(2-3), 67(2002).

6. S.M. Sinaga, S. Sudarmi , I. Iksen, K. Kevin and M.P. Sari, Rasayan J. Chem., 11(4), 1604(2018).

7. W. R. Bidlack, S.T. Omaye, M.S. Meskin, D.K.W. Topham, Phytochemicals As Bioactive Agents, CRC Press(2000). 


\section{RASĀYAN J. Chem.}

Vol. 12 | No. 1 |123 - 137| January - March | 2019

8. R.J. Ruch, S.J. Cheng,J.E. Klaunig,Carcinogens, 10, 1003(1989).

9. S. Hossain, M. Hossain, Ziaul-Haque, M.M.P.K. Uddin, Int. J. Bioassays., 4(01), 3606(2015).

10. I. Fidrianny, A. Rahmawati, and R. Hartati, Rasayan J. Chem., 11(4), 1628(2018), DOI: 10.31788/RJC.2018.1143091

11. J.B. Harborne, 1998, Phytochemical methods, in: A Guide to Modern Techniques of Plant Analysis, 3rd ed.: Chapman and Hall, London.

12. C.P. Victório, C.L.S Lage, R.M. Kuster. Ecl Quím São Paulo, 34(1), 19(2009), DOI: 10.1590/S010046702009000100003

13. B. Renuka, B. Sanjeev, D. Ranganathan. Journal of Pharmacognosy and Phytochemistry, 5(2), 105(2016).

14. G. Jayapriya, F.G. Shoba, Journal of Pharmacognosy and Phytochemistry,4(1), 113(2015).

15. G.S. Ćetković, S.M. Đilas, J.M. Čanadanović-Brunet, V.T. Tumbas. APTEFF, 34, 93(2003), DOI: 10.2298/APT0334093C

16. A. Gangwal, International Journal of Pharmaceutical and Chemical Sciences,2(3), 1366(2013).

17. H. Jahangirian, M. D. J. Haron, M. H. S. Ismail, R. Rafiee-Moghaddam, L. Leiliafsah-Hejri, Y. Abdollahi, M. Rezayi, N. Vafaei, Digest Journal of Nanomaterials and Biostructures, 8(3), 1263 (2013).

18. E. Déziel, F. Lepine, S. Milot, R. Villemur, Microbiology, 149, 2005(2003), DOI: 10.1099/mic.0.26154-0.

19. J. Tremblay, A.P. Richardson, F. Lepine, E. Deziel. Environ Microbiol, 9, 2622(2007), DOI: 10.1111/j.1462-2920.2007.01396.x

20. C. O'May, N, Tufenkji, Appl. Environ. Microbiol.,77(9), 3061(2011), DOI: 10.1128/AEM.02677-10

21. A.V. Samrot,K. Sahiti, P. Raji, B. Rohan, D. Kumar, K. Sharma, Der Pharmacia Lettre, 8(9), 41 (2016).

22. N. Ravisankar, C. Sivaraj, S. Seeni, J. Joseph, N. Raaman, Int. J. Pharm. Pharm Sci., 6(4), 456(2014).

23. J. Senguttuvan, S. Paulsamy, K. Karthika. Asian Pac. J. Trop. Biomed., 4(1), S359(2014), DOI: 10.12980/APJTB.4.2014C1030

24. N. Jadid, D. Hidayati, S. R. Hartantii, B. A. Arraniry, R.Y. Rachman, W. Wikanta, AIP Conference Proceedings, 1854, 020019 (2017), DOI:10.1063/1.4985410.

25. P Prieto, Pineda M, M. Anguilar, Anal. Biochem., 269, 337 (1999), DOI: 10.1006/abio.1999.4019

26. I. C. Parsons, A.I. Gary, P.G. Waterman, T.G. Hartely, J. Nat. Prod., 56(1), 46(1993), DOI: 10.1021/np50091a007

27. H. Liu, S. Sun, G. Lv, K. K. C. Chan, Spectrochimica Acta Part A, 64, 321 (2006), DOI: 10.1016/j.saa.2005.07.026

28. K. Jyoti, M. Baunthiyal, A. Singh, Journal of Radiation Research and Applied Sciences, 9, 217(2016), DOI:10.1016/j.jrras.2015.10.002

29. J.A. Duke, Handbook of Phytochemical Constituents of GRAS Herbs and other Economic Plants. Herbal Reference Library, Boca Raton, Fla: CRC Press (1999).

30. M. Sonam, R.P. Singh, S. Pooja, International Journal of Pharmacognosy and Phytochemical Research, 9(4), 523(2017).

31. D. Karou, A. Savadogo, A. Canini, S. Yameogo, C.M.J. Simpore, V. Colizzi, A.S. Traore, Afr. J. Biotechnol, 4(12), 1452(2005), DOI:10.5897/AJB2005.000-3192

32. B. M. Hariri, D.B. McMahon, B. Chen, N.D. Adappa, J. N. Palmer, D.W. Kennedy, R.J. Lee, PLOS ONE, 12(9), e0185203 (2017), DOI:10.1371/journal.pone.0185203.

33. A. V. Samrot, H. Sherly, K. Sahiti, B. D. Rohan, P. Raji, International Journal of Pharmaceutical and Phytopharmacological Research,6(1),1(2016).

34. J. S. Wright, E.R. Johnson, G.A. Di Labio. J. Am. Chem. Soc., 123(6), 1173(2001), DOI: $10.1021 / \mathrm{ja} 002455 \mathrm{u}$

35. E. Bendary, R.R. Francis, H.M.G. Ali, M.I. Sarwat, S. El-Hady, Annals of Agricultural Science, 58(2), 173(2013), DOI: 10.1016/j.aoas.2013.07.002.

[RJC-4054/2018] 